\title{
Transcription Characteristics of Mold Surface Topography in the Molding of Aspherical Glass Lenses
}

\author{
Du-Hwan Cha, Yeon Hwang, Jeong-Ho Kim, and Hye-Jeong Kim* \\ Ultra-precision Optics Team, Korea Photonics Technology Institute (KOPTI), ChumDan 4-ro 5 \\ Wolchul-Dong, Buk-Gu, Gwangju 500-779, Korea
}

(Received May 18, 2009 : revised June 9, 2009 : accepted June 9, 2009)

\begin{abstract}
The transcription characteristics of the mold surface in the molding of aspherical glass lenses for camera phone modules have been investigated experimentally. The surface topographies of both the form and the roughness were compared between the mold and the molded lens. For the form topography, the molded lens showed a transcription ratio of $93.4 \%$ against the mold, which is obtained by comparing the form error (PV) values of the mold and the molded lens. The transcription characteristics of the roughness topography were ascertained by bearing ratio analysis.
\end{abstract}

Keywords: Aspherical glass lens, Glass molding press (GMP), Transcription characteristics, Bearing ratio analysis

OCIS codes : (220.4610) Optical fabrication; (240.6700) Surfaces; (220.1250) Aspherics; (220.3630) Lenses

\section{INTRODUCTION}

Aspherical glass lenses offer many optical advantages, including superior optical performance and reduced optical aberrations. The key process used for aspherical glass lens fabrication in conventional lens manufacturing is polishing. Magnetorheological finishing (MRF) and precision polishing are two automatic polishing methods that are commercially available. Due to the complexity of these processes and the long cycle times involved, the overall costs for medium- to high-volume productions of aspherical lenses are very high [1-4].

The use of a glass molding press (GMP) has recently become an attractive alternative to the traditional glass lens manufacturing process-polishing. This hot-forming compression method has many advantages. For instance, it is a simpler process than polishing and lenses can be pressed into shape without requiring the usual subsequent finishing operations. Finally, it allows the fabrication of aspherical glass lenses that cannot be created using the polishing process.

The GMP method has made possible the mass production of aspherical glass lenses. Thus, in cases where

*Corresponding author: kimhj@kopti.re.kr the process parameters are properly designed, the GMP method is considered to be one of the most reliable methods for the fabrication of aspherical glass lenses. However, due to the extremely high hardness (Rockwell hardness $(\mathrm{Rc})>90$ ) of popular mold materials such as tungsten carbide (WC) and silicon carbide $(\mathrm{SiC})$, the grinding process used to fabricate such molds becomes expensive. In addition, it is sometimes difficult to control the many parameters of the molding process (e.g., the pressing force, cooling rate, and cooling range, etc.). To optimize the process parameters for that GMP process, it should be preceded by verification of the transcription characteristics of the mold surface onto the lens molded under a molding condition.

We investigated how to transcribe both the form and roughness of the aspherical surface of the mold onto the molded lens surface in the molding of aspherical glass lens for a camera phone module. In the case of the roughness transcription, the bearing ratio analysis was employed to obtain further surface details. Bearing ratio curves and parameters $\left(\mathrm{R}_{\mathrm{k}}, \mathrm{R}_{\mathrm{pk}}, \mathrm{R}_{\mathrm{vk}}, \mathrm{Mr}_{1}, \mathrm{Mr}_{2}\right.$, etc) have been widely used for analyzing the surface roughness and tribological performance of components [5]. As Fig. 1 shows, the bearing ratio curve is mathematically the integral of the amplitude distribution func- 


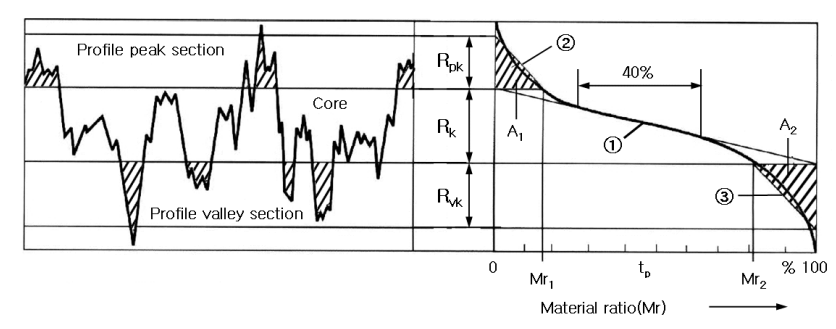

FIG. 1. Characteristics of the bearing ratio curve.

TABLE 1. Processing conditions for the fabrication of the tungsten carbide mold.

\begin{tabular}{l|l}
\hline \hline Grinding process & \\
\hline Wheel configuration & SD 2000, Resin bond \\
\hline Workpiece speed & $200 \mathrm{rpm}$ \\
\hline Grinding wheel speed & $30,000 \mathrm{rpm}$ \\
\hline Feed rate & $0.25 \mathrm{~mm} / \mathrm{min}$ \\
\hline Depth of cut & $0.1 \mu \mathrm{m}$ \\
\hline Polishing process & \\
\hline $\begin{array}{l}\text { Diamond paste } \\
\text { (Grain size) }\end{array}$ & Rough: $2 \mu \mathrm{m} ;$ Finish: $1 \mu \mathrm{m}$ \\
\hline Polishing medium & Nylon \\
\hline
\end{tabular}

TABLE 2. Thermal properties of the glass for molding.

\begin{tabular}{l|l}
\hline \hline Transition temperature $\left(\mathrm{T}_{\mathrm{g}}\right)$ & $498{ }^{\circ} \mathrm{C}$ \\
\hline Yielding point $\left(\mathrm{A}_{\mathrm{t}}\right)^{\circ} \mathrm{C}$ & $549{ }^{\circ} \mathrm{C}$ \\
\hline Annealing point $(\mathrm{AP})$ & $488{ }^{\circ} \mathrm{C}$ \\
\hline Strain point $(\mathrm{StP})$ & $464{ }^{\circ} \mathrm{C}$ \\
\hline
\end{tabular}

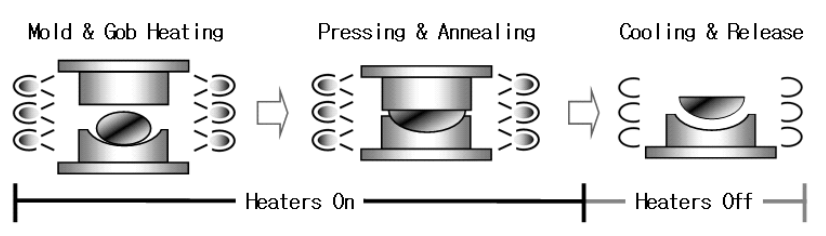

FIG. 2. Schematic illustration of GMP process.

tion [6]. It is a cumulative probability distribution. The construction of $R_{k}$ parameter is designed to divide the bearing ratio curve into three sections; the small peaks above the main plateaus $\left(\mathrm{R}_{\mathrm{pk}}\right)$, the plateaus themselves $\left(\mathrm{R}_{\mathrm{k}}\right)$, and the deep valleys below the plateaus $\left(\mathrm{R}_{\mathrm{vk}}\right)$.

The following mathematical expression to describe the bearing ratio curve of a profile has been proposed by Kragelskii [7], as :

$$
t_{p}=b\left(\frac{a}{R_{t}}\right)^{v}
$$

where $t_{p}$ is the bearing curve parameter at a certain depth (\%), $R_{t}$ is the maximum height of the profile $(\mu \mathrm{m})$, and $a$ is the depth below the upper reference line. The coefficients $b$ and $v$ are determined experimentally.

\section{EXPERIMENTAL}

\section{Lens design and mold fabrication}

The aim was to produce a plano-aspherical convex singlet lens with a diameter of $4.0 \mathrm{~mm}$ (clear aperture $3.0 \mathrm{~mm}$ ), intended for a 3-megapixel, 2.5 magnification zoom camera phone module. The aspherical convex side of the lens was optically designed using the following aspherical equation:

$$
z=\frac{C \cdot x^{2}}{1+\sqrt{1-(1+K) \cdot C^{2} \cdot x^{2}}}+\sum_{i=1}^{n} A_{i} \cdot x^{i}
$$

where $K(=-0.298)$ is the conic constant, $C=1 / R$ (where $R[=2.934 \mathrm{~mm}]$ is the vertex radius of the aspherical surface), and $\mathrm{A}$ is the constant for the aspherical form.

Tungsten carbide (WC; 002K, Everloy Co., Japan) that contained 0.5 wt.\% cobalt (Co) was used to build the mold. The mold surface was ground and polished using an ultra-precision aspherical processing machine (ASP01, Nachi-Fujikoshi Co., Japan) and an aspherical polishing machine (KRF-2200F, Kuroda Co., Japan), respectively. Diamond-like carbon (DLC), $80 \mathrm{~nm}$ in thickness, was coated onto the processing surface in order to protect the mold from the extreme working conditions during the molding process. The aspherical surface of the fabricated mold showed form error (PV) of 0.199 $\mu \mathrm{m}$. All of the mold surface processing conditions are summarized in Table 1 for completeness.

\section{The GMP process and surface analysis}

A ball-type preform (L-BSL7, Ohara Co., Japan) was used as the glass material for the lens fabrication. The thermal properties of this glass are shown in Table 2. This and other glasses suitable for the GMP lens fabrication method have lower transition temperature than standard glasses, and they are lead $(\mathrm{Pb})$ free. A GMP process is a hot-forming compression method, which can be grouped roughly into three steps. Figure 2 and Table 3 show the schematic of the sequence of a generic GMP process and the details of the molding condition in this study, respectively. In the first step, nitrogen gas is purged into the molding chamber, and the mold assembly and a glass preform are heated to a molding temperature slightly higher than the yielding temperature. The viscosity of the glass preform, at this time, is softened to $10^{7}-10^{9} \mathrm{P}$. In the second step, the glass preform is pressed into a glass lens at a constant temperature and then immediately cooled slowly with 
TABLE 3. The molding conditions of the molded lens used in this study.

\begin{tabular}{c|c|c|c|c}
\hline \hline \multirow{2}{*}{ Parameter } & \multirow{2}{*}{$\begin{array}{c}\text { Delay } \\
\text { time }\end{array}$} & \multicolumn{2}{|c|}{ Pressing process } & \multirow{2}{*}{$\mathrm{SC}^{*}$ process } \\
\cline { 3 - 5 } & Step 1 & Step 2 & \\
\hline Force $(\mathrm{N})$ & - & 100 & 300 & 200 \\
\hline Time (sec) & 30 & 10 & 10 & - \\
\hline $\begin{array}{c}\text { Temperature } \\
\left({ }^{\circ} \mathrm{C}\right)\end{array}$ & Molding & $\mathrm{SC}^{*}$ range & Release & $\begin{array}{c}\text { Rate } \\
\left({ }^{\circ} \mathrm{C} / \mathrm{sec}\right)\end{array}$ \\
\cline { 2 - 5 } & 555 & $555-460$ & 200 & 0.4 \\
\hline
\end{tabular}

*SC : Slow Cooling
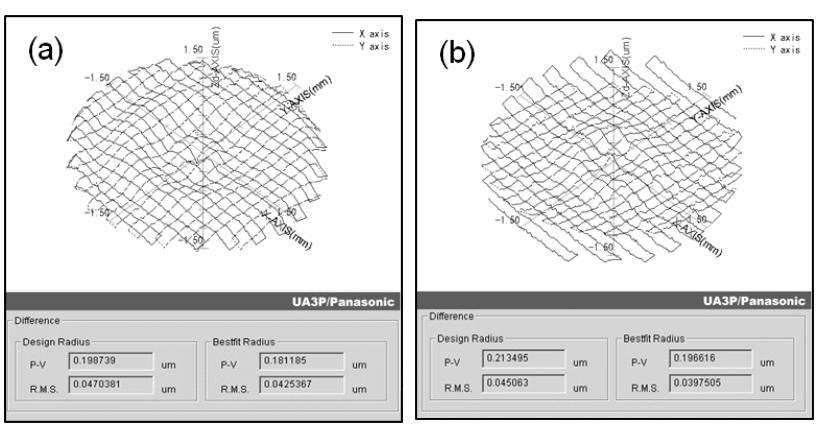

FIG. 3. Form error (PV) of the aspherical surfaces of: (a) the mold and (b) the molded lens.

pressing to minimize the form error. In general, the slow cooling step in the GMP process involves cooling from above the annealing point to below the strain point. In the last step, rapid cooling takes place and the molded lens is eventually released at about $200^{\circ} \mathrm{C}$.

Ten test lenses were molded under the same condition using a precision glass molding machine (Nano Press-S, Sumitomo Co., Japan). The form error (PV) of each aspherical surface was measured using an ultra-high accuracy three-dimensional (3-D) profilometer (UA3P, Panasonic Co., Japan), and the surface roughness (Ra) was measured with a white light interferometer (Newview 5000, Zygo Co., USA) with a vertical resolution of $0.1 \mathrm{~nm}$.

\section{EXPERIMENTAL RESULTS}

\section{Transcription characteristics of mold surface; form topography}

The form error (PV) of the molded lens was measured using an ultra-high accuracy 3 -D profilometer, which operates using the repulsive forces between the atoms of the scanning probe and the test surface. The measured form error (PV) values for the aspherical surfaces of the mold and the molded lens are depicted in Fig. 3 (a) and (b), respectively. The form error (PV) values of the mold and the molded lens are found to be 0.199 $\mu \mathrm{m}$ and $0.213 \mu \mathrm{m}$ to the design form, respectively. The percentage transcription ratio is calculated as the ratio
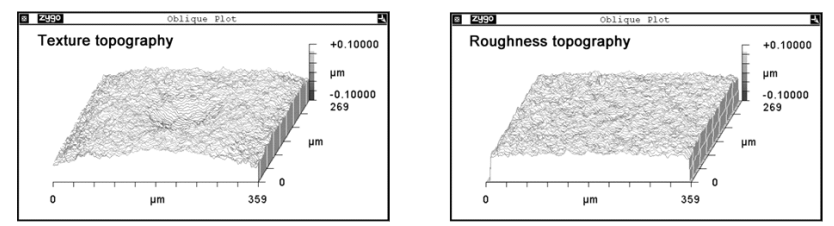

(a)
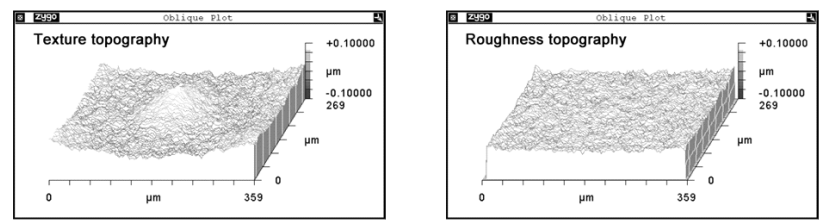

(b)

FIG. 4. 3-D surface views before and after filtering the texture topography of: (a) the mold and (b) the molded lens.

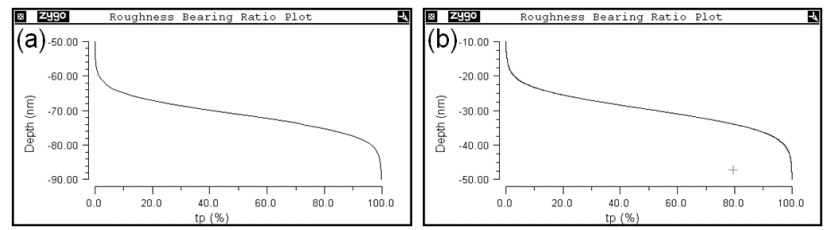

FIG. 5. Bearing ratio curves for: (a) the mold and (b) the molded lens.

of the form error (PV) to the design form between the mold and the molded lens. It is calculated to be around $93.4 \%$.

\section{Transcription characteristics of mold surface; roughness topography}

The surface roughness (Ra) of 3-D topography was measured using a white light interferometer, which captures and measures the microstructure and topography of surfaces in three dimensions. To obtain the surface roughness $(\mathrm{Ra})$, the noise in the raw data is removed by the $\lambda_{s}$ cutoff and the roughness topography is maintained by the $\lambda_{c}$ cutoff. The cutoff lengths chosen were $2.67 \mu \mathrm{m}\left(\lambda_{\mathrm{s}}\right)$ and $80 \mu \mathrm{m}\left(\lambda_{\mathrm{c}}\right)$ based on the ISO 3274 standard. The measured surface roughnesses (Ra) of the mold and the molded lens were $3.97 \mathrm{~nm}$ and $4.20 \mathrm{~nm}$, respectively. Figure 4 shows 3 -D surface views before and after filtering the texture topography of the mold (a) and the molded lens (b).

The surface roughness value $(\mathrm{Ra})$ does not provide all of the possible surface information. Therefore, bearing ratio analysis was carried out to obtain more detailed surface roughness data. Figure 5 and Table 4 show the bearing ratio curves of the mold and the molded lens and the related parameters. A comparison of the bearing ratio parameters of the mold and the molded lens in the Table 4 reveals more detailed transcription properties of the roughness topography. Because the peak section 
TABLE 4. Bearing ratio parameters of the mold and the molded lens.

\begin{tabular}{c|c|c|c}
\hline \hline $\begin{array}{c}\text { Bearing ratio } \\
\text { parameter }\end{array}$ & Mold & Molded lens & Unit \\
\hline $\mathrm{R}_{\mathrm{k}}$ & 12.36 & 13.09 & $\mathrm{~nm}$ \\
\hline $\mathrm{R}_{\mathrm{pk}}$ & 5.53 & 5.09 & $\mathrm{~nm}$ \\
\hline $\mathrm{R}_{\mathrm{vk}}$ & 6.99 & 5.25 & $\mathrm{~nm}$ \\
\hline $\mathrm{Mr}_{1}$ & 9.66 & 9.82 & $\%$ \\
\hline $\mathrm{Mr}_{2}$ & 89.74 & 89.62 & $\%$ \\
\hline $\mathrm{Mr}_{2}-\mathrm{Mr}_{1}$ & 80.08 & 79.8 & $\%$ \\
\hline $100-\mathrm{Mr}_{2}$ & 10.26 & 10.38 & $\%$ \\
\hline $\mathrm{A}_{1}$ & 0.09 & 0.69 & $\mu \mathrm{m}^{2}$ \\
\hline $\mathrm{A}_{2}$ & 0.13 & 0.75 & $\mu \mathrm{m}^{2}$ \\
\hline
\end{tabular}

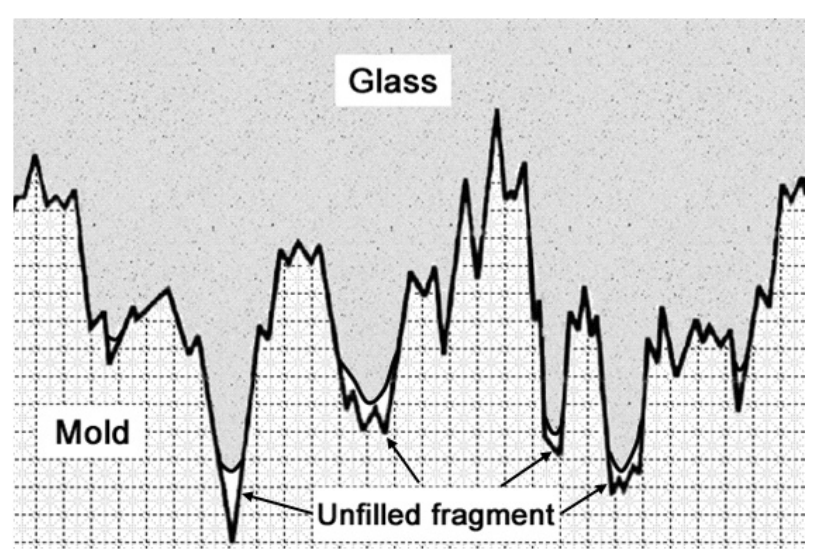

FIG. 6. Schematic interface between the mold and the glass in the pressing process.
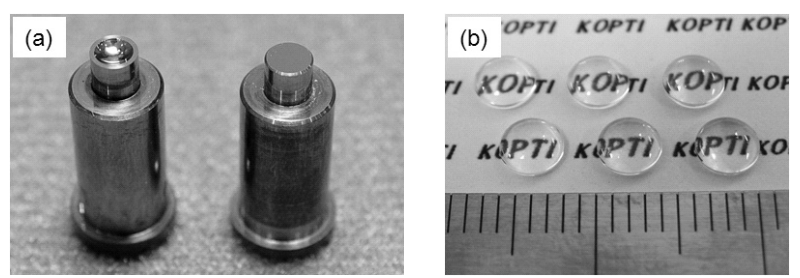

FIG. 7. Photos: (a) the WC mold and (b) the molded lenses.

of the mold was transcribed on the valley section of the molded lens and the valley section was transcribed on the peak section, great care must be taken when comparing the parameters between the mold and the molded lens. The values of the parameters have to be compared to each other as follows:

$$
\begin{aligned}
& \mathrm{R}_{\text {k-lens }}-\mathrm{R}_{\text {k-mold }} \quad \mathrm{R}_{\mathrm{pk} \text {-lens }}-\mathrm{R}_{v k \text {-mold }} \\
& \mathrm{R}_{v k \text {-lens }}-\mathrm{R}_{\text {pk-mold }} \quad \mathrm{Mr}_{1 \text { lens }}-\left(100-\mathrm{Mr}_{2}\right) \\
& \left(\mathrm{Mr}_{2}-\mathrm{Mr}_{1}\right)_{\text {lens }}-\left(\mathrm{Mr}_{2}-\mathrm{Mr}_{1}\right)_{\text {mold }} \\
& \left(100-\mathrm{Mr}_{2}\right)_{\text {lens }}-\mathrm{Mr}_{\text {1mold }}
\end{aligned}
$$

$$
\mathrm{A}_{\text {1lens }}-\mathrm{A}_{\text {2mold }} \quad \mathrm{A}_{\text {2lens }}-\mathrm{A}_{\text {1mold }}
$$

The values of the absolute area parameters $\left(A_{1}\right.$ and $A_{2}$ ) for the molded lens are higher than those for the mold. This shows that the increased surface roughness (Ra) of the molded lens was caused by both the peak and valley sections. By comparing the parameters between the mold and the molded lens, the following three results were obtained:

- For the mold, the peak area $\left(A_{\text {1mold }}\right)$ was less than the valley area $\left(A_{2 m o l d}\right)$. Therefore, for the molded lens, the peak area $\left(A_{\text {llens }}\right)$ was expected to be greater than the valley area $\left(A_{\text {2lens }}\right)$. However, the peak area on the molded lens is less than the valley area.

- For the molded lens, the material ratio of both the core $\left(\left(\mathrm{Mr}_{2}-\mathrm{Mr}_{1}\right)\right.$ lens $)$ and the peak $\left(\mathrm{Mr}_{\text {llens }}\right)$ sections were decreased compared to the corresponding parameters of the mold, but that of the valley section $\left(100-\mathrm{Mr}_{\text {2lens }}\right)$ was increased.

- The $\mathrm{R}$ parameter value of the valley section in the mold $\left(R_{v k-m o l d}\right)$ is comparatively higher than that of the peak section in the molded lens $\left(R_{p k-l e n s}\right)$; other $\mathrm{R}$ parameters are relatively similar. This observation indicates that the depth of the peak section on the molded lens is more uniform than that of the valley section on the mold.

The above results suggest that the peak section of the mold is more finely transcribed on the glass surface than the valley and core sections, as shown in Fig. 6. This figure depicts the assumed interface between the mold and the glass during the pressing process. Figure 7 shows photos of the fabricated mold (a) and the molded lenses (b).

\section{CONCLUSION}

(1) For the form topography, the molded lens showed a transcription ratio of $93.4 \%$. This value is obtained by comparing the form error (PV) values of the mold and the molded lens. This value is sufficient for fabricating the precision optical component for our system.

(2) The molded lens has a rougher surface $(4.20 \mathrm{~nm}$ $\mathrm{Ra})$ than the mold $(3.97 \mathrm{~nm} R a)$. This phenomenon is understood by comparing the absolute area parameters (A1 and A2) between the mold and the molded lens; the values of both $A 1$ and $A 2$ for the molded lens were higher than those for the mold.

(3) The peak section of the mold surface was more finely transcribed onto the glass surface than the other sections (the core and the valley sections). 


\section{REFERENCES}

1. R. G. Bingham, D. D. Walker, D. H. Kim, D. Brooks, R. Freeman, and D. Riley, "A novel automated process for aspherical surfaces," Proc. SPIE 4093, 4445-4448 (2000).

2. S. D. Jacobs, Innovations in Polishing of Precision Optics, H. Ohmori and H. M. Shimizi, ed. (Universal Academy Press Inc., Tokyo, Japan, 2003).

3. D. H. Cha, H. J. Kim, H. U. Kim, S. S. Kim, Y. P. Park, and J. H. Kim, "Fabrication and optical evaluation of aspheric glass lenses for 3 megapixel zoom camera phone module," Optical Review 14, 145-150 (2007).

4. S. H. Chang, Y. M. Lee, K. H. Shin, and Y. M. Heo, "A study on the aspherical glass lens forming analysis in the progressive GMP process," J. Opt. Soc. Korea 11, 85-92 (2007).

5. D. J. Whitehouse, Handbook of Surface Metrology (Institute of Physics Publishing for Rank Talyor-Hobson, Bristol, UK, 1996).

6. D. Prostrednik and P. H. Osanna, "The Abbott curvewell know in metrology but not on technical drawings," Int. J. Mach. Tools Manufact. 38, 741-745 (1998).

7. I. V. Kragelskii, Tribology Handbook (Mir Publishers, Moscow, Russia, 1981). 